\title{
Effects of Polysaccharide-Based Edible Coatings on Quality and Antioxidant Enzyme System of Strawberry during Cold Storage
}

\author{
Li Li, ${ }^{1,2}$ Jian Sun, ${ }^{1,2}$ Haiyan Gao, ${ }^{3}$ Yingbin Shen, ${ }^{4}$ Changbao Li, ${ }^{1,2}$ Ping Yi, ${ }^{1}$ \\ Xuemei He, ${ }^{1}$ Dongning Ling, ${ }^{1}$ Jinfeng Sheng, ${ }^{1}$ Jiemin Li, ${ }^{1}$ Guoming Liu, ${ }^{1}$ Fengjin Zheng, \\ Ming Xin, ${ }^{1}$ Zhichun Li, $^{1}$ and Yayuan Tang ${ }^{1}$
}

\author{
${ }^{1}$ Agro-Food Science and Technology Research Institute, Guangxi Academy of Agricultural Sciences, Nanning, China \\ ${ }^{2}$ Guangxi Key Laboratory of Fruits and Vegetables Storage-Processing Technology, Nanning, China \\ ${ }^{3}$ Food Science Institute, Zhejiang Academy of Agricultural Sciences, Hangzhou, China \\ ${ }^{4}$ Department of Food Science and Engineering, Jinan University, Guangzhou, China
}

Correspondence should be addressed to Jian Sun; jiansun@gxaas.net

Received 30 August 2017; Accepted 16 November 2017; Published 11 December 2017

Academic Editor: Chaoqun Zhang

Copyright (C) $2017 \mathrm{Li} \mathrm{Li}$ et al. This is an open access article distributed under the Creative Commons Attribution License, which permits unrestricted use, distribution, and reproduction in any medium, provided the original work is properly cited.

\begin{abstract}
Strawberry is a nutritious, but highly perishable fruit. Three polysaccharide-based edible coatings (alginate, chitosan, and pullulan) were applied to postharvest strawberry fruit during cold storage $\left(4^{\circ} \mathrm{C}\right)$, and their effects on fruit quality and antioxidant enzyme system were investigated in the present study. The results showed that polysaccharide coatings showed a significant delay in fruit softening and rot and reduced changes in total soluble solid and titratable acidity content during $16 \mathrm{~d}$ storage. Polysaccharide coatings also maintained higher ascorbic acid and total phenolic contents than control from day 2 and significantly inhibited fruit decay and respiration after $12 \mathrm{~d}$ storage $(p<0.05)$. Polysaccharide treatments enhanced the activities of antioxidant enzymes (peroxidase, catalase, superoxide dismutase, and ascorbate peroxidase) so as to prevent lipid peroxidation and reduce membrane damage. Additionally, chitosan coating had the most positive effects on fruit quality amongst three polysaccharide-based edible coatings and presented the highest relative activities of antioxidant enzymes. These results indicated that polysaccharide-based edible coatings were helpful in postharvest quality maintenance of strawberry fruit.
\end{abstract}

\section{Introduction}

Strawberry (Fragaria $\times$ ananassa Duch.) is one of the most consumed nonclimacteric fruits due to its organoleptic and nutritional properties [1]. However, strawberry is extremely perishable with a short postharvest life, mainly because of high metabolism as well as susceptibility to mechanical damage and infection by phytopathogenic bacteria, fungi, and viruses [2]. Many preservation techniques such as refrigeration, heat treatment, and modified or controlled atmosphere have been applied to increase strawberry shelf life [3]. Most physical treatments have showed potential negative effects on nutritional and flavor components in this fruit [4]. Therefore, it is necessary to explore and utilize new techniques for maintaining postharvest strawberry fruit quality.

Active edible coating is a novel promising approach for extending shelf life of fruits and vegetables [5]. Edible coatings with semipermeable film can prolong postharvest fruit life through reducing moisture, respiration, gas exchange, and oxidative reaction rates [6]. The application of polysaccharide-based edible coatings enriched with antimicrobials or antioxidants has been proved to be efficacious in preserving fruit quality during storage $[7,8]$. Alginate, chitosan, and pullulan are often used as polysaccharide-based edible coatings due to their capacity to form rigid and stable gels $[9,10]$. Alginate, a polysaccharide derived from marine brown algae (Phaeophyceae) and gellan or secreted by bacterium Sphingomonas elodea, is employed in food industry as texturizing and gelling agent [11]. Chitosan, a highmolecular-weight polysaccharide obtained by deacetylation of chitin, is a byproduct of seafood industry. Chitosanbased coatings have been found to be an ideal preservative coating material for different types of fruits, with functional advantages such as storage period extension, respiration 
rate reduction, firmness retention, and microbial growth regulation [12]. Pullulan, produced by fungus Aureobasidium pullulans, is a water-soluble polysaccharide with excellent film-forming properties [13]. It can form edible films with antioxidant and antibacterial activities and without any taste or aroma.

Peroxidation activities are directly involved in natural and induced fruit senescence. Antioxidant enzymes are critical in inhibiting oxidative stress. When reactive oxygen species (ROS) increases, chain reactions start in which superoxide dismutase (SOD) catalyzes the dismutation of superoxide radical $\left(\mathrm{O}_{2}{ }^{--}\right)$to molecular oxygen $\left(\mathrm{O}_{2}\right)$ and hydrogen peroxide $\left(\mathrm{H}_{2} \mathrm{O}_{2}\right) . \mathrm{H}_{2} \mathrm{O}_{2}$ is then detoxified by catalase (CAT), peroxidase (POD), and ascorbate peroxidase (APX) [14]. CAT reduces $\mathrm{H}_{2} \mathrm{O}_{2}$ into water and $\mathrm{O}_{2}$, whereas POD decomposes $\mathrm{H}_{2} \mathrm{O}_{2}$ by oxidation of cosubstrate such as phenolic compounds [15]. It is important to note that the effect of polysaccharide coatings (e.g., alginate, pullulan, and chitosan) on antioxidant enzyme system of strawberry has not been studied up to date. The objective of this study was thus to determine how polysaccharide-based edible coatings affected quality and antioxidant enzyme system of strawberry during cold storage. The molecular characterization of polysaccharide-based edible coatings in response to senescence was also analyzed. The study results were useful for maintaining postharvest quality and extending storage life of strawberry.

\section{Materials and Methods}

2.1. Plant Materials and Treatments. Strawberries (Fragaria $\times$ ananassa Duch. cv. Sweet Charlie) were harvested at full maturity at an orchard in Nanning of Guangxi province during March 2017 and transported to Guangxi Key Laboratory of Fruits and Vegetables Storage-Processing Technology immediately. The fruits with physical damage or decay were discarded, and those fruits with uniform size and color were selected as materials. Subsequently, strawberry materials were randomly distributed into four groups prior to treatments. Three different polysaccharide-based coating-forming solutions ( $1 \%$ alginate, $6.5 \%$ pullulan, and $2 \%$ chitosan) were prepared by dissolving compounds in sterile distilled water under magnetic stirring. Strawberries were sanitized for $1 \mathrm{~min}$ with a $200 \mathrm{mg} / \mathrm{kg}$ chlorinated water solution, dipped in polysaccharide-based coating-forming solutions for $5 \mathrm{~min}$, and then dried for $30 \mathrm{~min}$ at room temperature. Coated strawberries were packed in the polyethylene terephthalate clamshell containers with venting holes and stored for $16 \mathrm{~d}$ at $4^{\circ} \mathrm{C}$. Uncoated strawberries were used as control at the same storage condition in all analyses.

\subsection{Fruit Quality Evaluation}

2.2.1. Decay Rate and Firmness. Decay rate was evaluated on a modified 0-3 decay scale based on the surface area of macroscopic lesions, where 3 meant unacceptable, more than $30 \%$ of surface area showing decay; 2 meant bad, $10-30 \%$ of surface area showing decay; 1 meant acceptable, less than $10 \%$ of surface area showing decay; 0 meant excellent, no visible decay detected [16]. The firmness of strawberries was measured using a FT-327 handheld penetrometer (UC Fruit Firmness Tester, Milano, Italy) equipped with a probe with $5 \mathrm{~mm}$ diameter. The firmness was recorded from three different fruits with three different points per fruit, and then means were expressed as Newtons (N).

2.2.2. Contents of Total Soluble Solid, Titratable Acidity, Ascorbic Acid, and Total Phenolic. Total soluble solid (TSS) level of strawberries was determined according to AOAC method [17], using a hand refractometer (Atago, Tokyo, Japan). Titratable acidity (TA) content was determined using an automatic titrator (Titroline Easy, Schott, Mainz, Germany) by titration of juice with $0.1 \mathrm{M} \mathrm{NaOH}$ to $\mathrm{pH}$ 8.2. Results were expressed as percentage of citric acid (grams of citric acid per $100 \mathrm{~g}$ fresh weight). Ascorbic acid (VC) content was determined by titrating $10 \mathrm{~g}$ of mixed pulp sample against the standard 2,6-dichlorophenol indophenol dye following procedure outlined in AOAC. Total phenolic content was determined by Folin-Ciocalteu method reaction using gallic acid as a standard with some modifications [18]. The samples were analyzed at $760 \mathrm{~nm}$ with a UV-160A spectrophotometer (Shimadzu, Kyoto, Japan), which were expressed as gallic acid equivalents in milligrams on FW basis.

2.2.3. Respiration Rate. Respiration rate for strawberries, exposed to pure $\mathrm{N}_{2}$ for 0 or $9 \mathrm{~h}$ and then stored at $20^{\circ} \mathrm{C}$ and $90 \%$ relative humidity, was determined after various storage days. Three fruits were sealed in a $4.2 \mathrm{~L}$ glass jar for $2 \mathrm{~h}$ at $25^{\circ} \mathrm{C}$. One milliliter of headspace gas samples was withdrawn from the jar and injected into a GC-9A gas chromatograph (Shimadzu). Carbon dioxide concentration was determined using a thermal conductivity detector (TCD) with a Porapak N column (Shimadzu), while ethylene content was measured using a flame ionisation detector (FID) and an OV17 capillary column (Zhonghuida Co., Dalian, China).

\subsection{Oxidative Stress Analysis}

2.3.1. Malondialdehyde Content and Lipoxygenase Activity. Malondialdehyde (MDA) content was measured according to the reported method of Sun et al. [14] with a slight modification. Strawberries ( $3 \mathrm{~g}$ ) were homogenized with $15 \mathrm{~mL}$ of $10 \%$ trichloroacetic acid and centrifuged for $20 \mathrm{~min}$ at $15000 \times \mathrm{g}$. One milliliter of supernatant was mixed with $3 \mathrm{~mL}$ of $0.5 \%$ 2-thiobarbituric acid, heated for $20 \mathrm{~min}$ at $95^{\circ} \mathrm{C}$, and then immediately cooled in an ice-water bath. The absorbance was spectrophotometrically measured at $532 \mathrm{~nm}$ (UV 1600 PC, Shimadzu) after centrifugation for $10 \mathrm{~min}$ at $3000 \times \mathrm{g}$, and the value for nonspecific absorbance at $600 \mathrm{~nm}$ was subtracted.

The frozen strawberries $(5 \mathrm{~g}$ ) were ground finely in liquid nitrogen and then homogenized in $15 \mathrm{~mL}$ of $50 \mathrm{mM}$ phosphate buffer $(\mathrm{pH} 7)$. After centrifugation at $10000 \times \mathrm{g}$ for $20 \mathrm{~min}$ at $4^{\circ} \mathrm{C}$, supernatant was collected and used as crude enzyme extract. LOX activity was assayed by monitoring the formation of conjugated dienes from linoleic acid at $25^{\circ} \mathrm{C}$ and $234 \mathrm{~nm}$ [15]. Reaction mixture ( $3 \mathrm{~mL}$ ) contained $50 \mathrm{mM}$ sodium phosphate buffer $(2.8 \mathrm{~mL}, \mathrm{pH}$ 7), $10 \mathrm{mM}$ sodium 


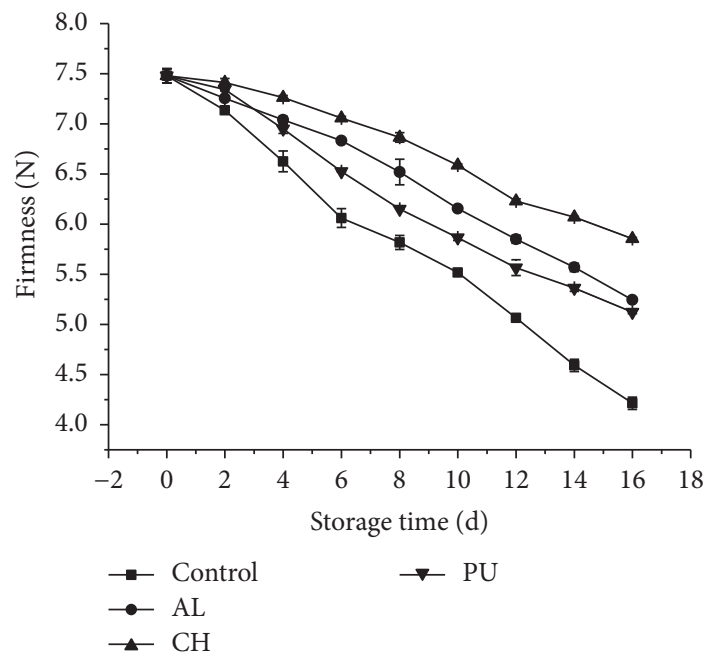

(a)

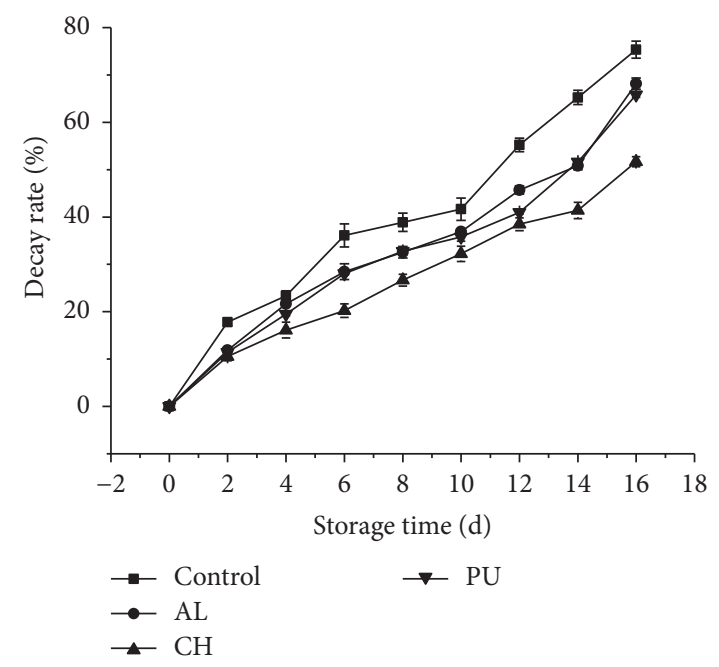

(b)

FIGURE 1: Effects of three different polysaccharide-based edible coatings on firmness (a) and decay rate (b) of strawberry.

linoleic acid solution $(0.1 \mathrm{~mL})$, and crude enzyme solution $(0.1 \mathrm{~mL})$.

2.3.2. Activities of Antioxidative Enzymes. POD, CAT, and APX were extracted according to the modified methods of Nakano and Asada [19]. Strawberries (1g) were extracted for $10 \mathrm{~min}$ at $4^{\circ} \mathrm{C}$ with $2.5 \mathrm{~mL}$ of $0.05 \mathrm{M}$ sodium phosphate buffer ( $\mathrm{pH} 7.8)$ containing $0.1 \%(\mathrm{w} / \mathrm{v})$ polyvinyl pyrrolidone. The extract solution was centrifuged for $20 \mathrm{~min}$ at $12000 \times \mathrm{g}$. The supernatant was collected to determine activities of POD, CAT, and APX according to the methods of Song et al. [20]. SOD was extracted and assayed according to the modified method of Azarabadi et al. [21]. SOD activity was determined by measuring its ability to inhibit the photochemical reduction of nitro blue tetrazolium (NBT).

2.4. Statistical Analysis. All experiments were performed in triplicate $(n=3)$ and were arranged in a completely randomized design. All statistical analyses were performed by variance (ANOVA) analysis using SPSS 13.0 statistical software (SPSS Inc., Chicago, USA). Significant differences between the means of parameters were determined by using Fisher's Least Significant Difference (LSD) test $(p<0.05)$.

\section{Results}

3.1. Effects of Polysaccharide-Based Edible Coatings on Firmness and Decay Rate of Strawberry. Firmness is one of critical factors affecting strawberry storage quality. The effects of three polysaccharide-based edible coatings on firmness were shown in Figure 1(a). The firmness values of coated fruits and control decreased with prolonged storage time due to cell wall degradation. Firmness loss in polysaccharide-coated fruit delayed significantly $(p<0.05)$ compared to control. It was observed that strawberries coated by chitosan were firmer than the other two treatments (alginate and pullulan). From Figure 1(b), strawberries exhibited a sharp increase in decay rate during $16 \mathrm{~d}$ storage at $4^{\circ} \mathrm{C}$. The decay rate of control remained significantly higher $(p<0.05)$ than that of polysaccharide-coated fruits after day 4 . Meanwhile, the decay rate of chitosan-coated fruits was significantly lower $(p<0.05)$ than that of alginate-coated and pullulan-coated fruits.

\subsection{Effects of Polysaccharide-Based Edible Coatings on Nutri-} ent Components of Strawberry. From Figure 2(a), TSS contents decreased during $16 \mathrm{~d}$ storage of all strawberries. On day 16 , TSS values of three polysaccharide-coated fruits were in the order of chitosan $>$ pullulan $>$ alginate. From Figure 2(b), TA contents in all fruits decreased with extended storage time. TA values in polysaccharide-coated fruits were significantly higher $(p<0.05)$ than those in control after day 6 . Chitosan-coated fruits showed the highest TA content during storage. From Figure 2(c), VC content decreased in all fruits during $16 \mathrm{~d}$ storage. Polysaccharide-coated fruits possessed relatively higher $(p<0.05)$ VC contents than control on days 8,14 , and 16 . Chitosan-coated fruits showed the highest VC content amongst three polysaccharide treatments after day 12. The higher VC level in chitosan-coated fruit might reflect low oxygen permeability, which reduced the activities of enzymes involved in the oxidation of ascorbic acid. From Figure 2(d), TP contents in all fruits decreased throughout storage time. TP values in polysaccharide-coated fruits were slightly higher than those in control. Chitosan-coated fruits showed the lowest decrease rate in TP content amongst three polysaccharide treatments after day 10 . The above results indicated that polysaccharide-based edible coatings had positive effect on maintaining strawberry fruit quality when storing at low temperature.

3.3. Effect of Polysaccharide-Based Edible Coatings on Respiration Rate of Strawberry. The increases of respiration rate could be related to fruit senescence and disease development during storage. Polysaccharide-coated fruits can generally 


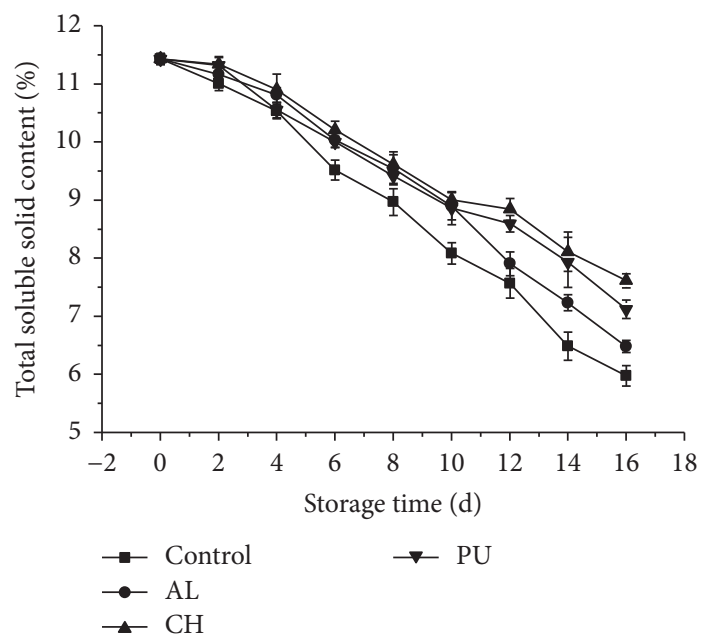

(a)

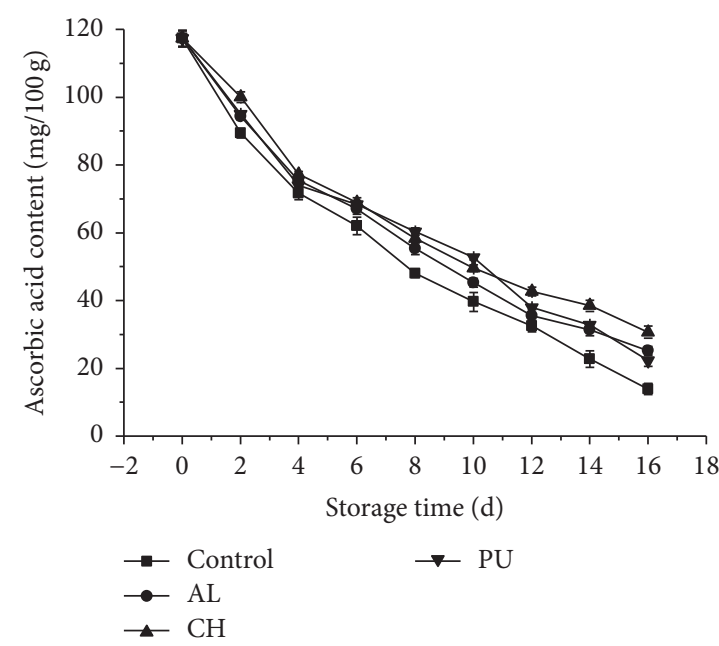

(c)

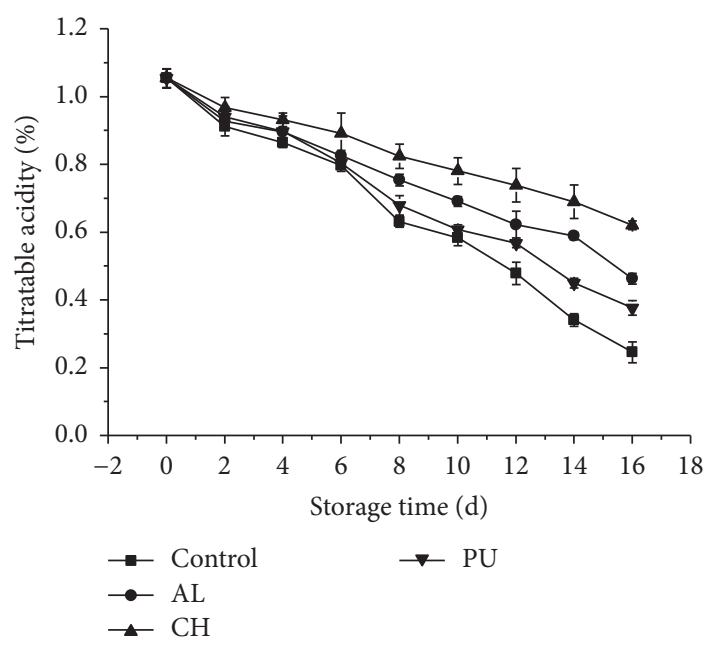

(b)

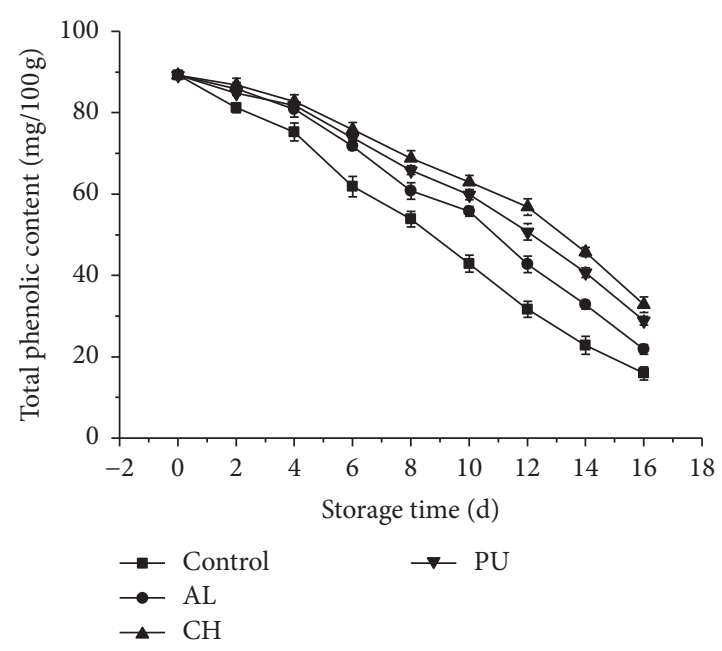

(d)

FIGURE 2: Effects of three different polysaccharide-based edible coatings on TSS (a), TA (b), VC (c), and TP (d) contents of strawberry.

delay ripening by modifying the levels of endogenous carbon dioxide, oxygen, and ethylene. From Figure 3, respiration rate exhibited increasing trends during storage of all fruits. Respiration rates in polysaccharide-coated fruits were slightly higher than those in control after $12 \mathrm{~d}$. In the case of control, respiration rate increased rapidly from an initial value of $3.8 \mathrm{mg} / \mathrm{kg} / \mathrm{h}$ to a peak value of $58.71 \mathrm{mg} / \mathrm{kg} / \mathrm{h}$ on day 16 , whereas alginate-coated, chitosan-coated, and pullulancoated fruits showed $45.59,38.03$, and $50.00 \mathrm{mg} / \mathrm{kg} / \mathrm{h}$ on day 16 , respectively.

\subsection{Malondialdehyde Content and Lipid Peroxidation Activity.} MDA content and LOX activity are used as measurements of membrane integrity loss in response to postharvest oxidative stress during storage [22]. The change of MDA level is considered to be a marker of membrane lipid peroxidation of fruits subjected to senescence or stress. From Figure 4, MDA contents of control increased quickly during storage. Polysaccharide coatings inhibited an increase of MDA

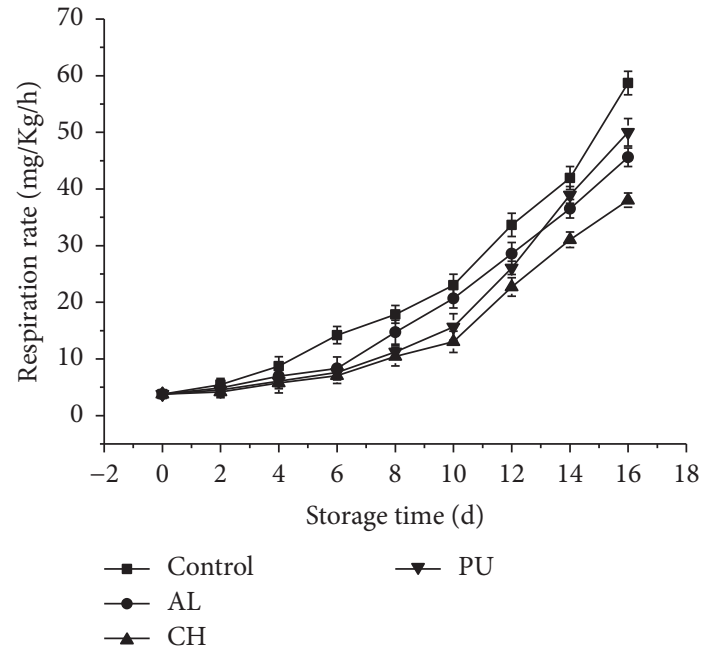

FIGURE 3: Effects of three different polysaccharide-based edible coatings on respiration rate of strawberry. 


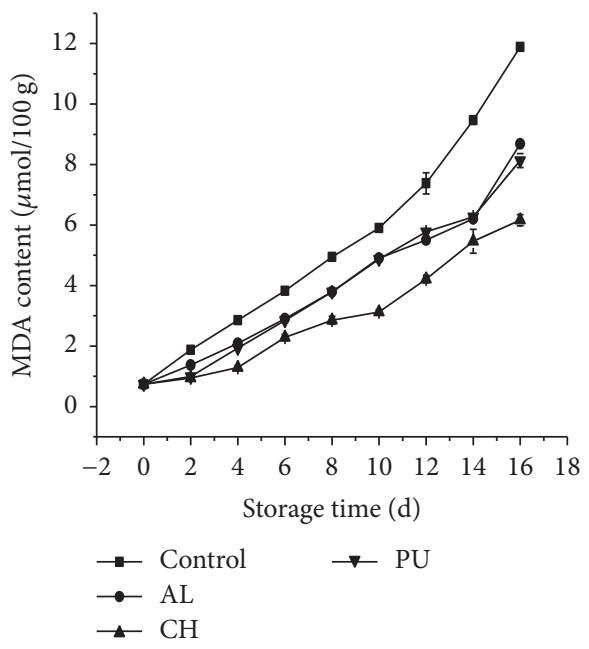

(a)

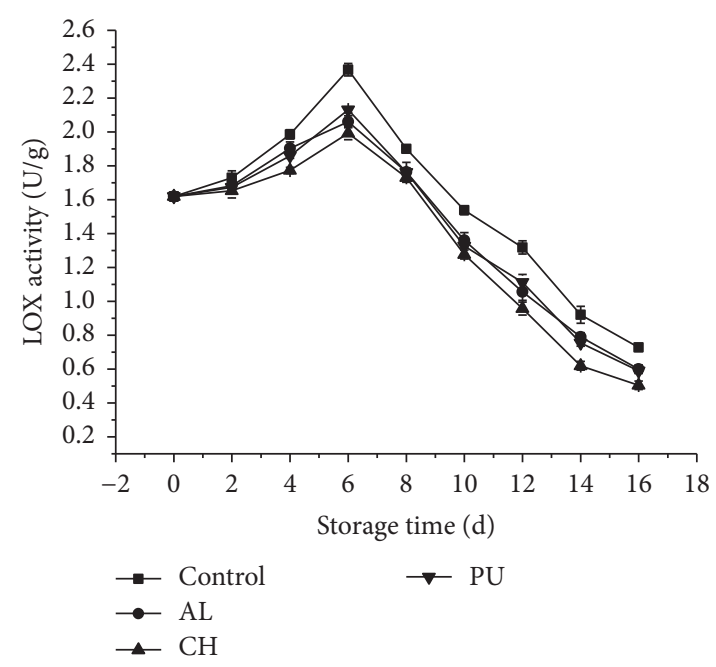

(b)

FIGURE 4: Effects of three different polysaccharide-based edible coatings on MDA content (a) and LOX activity (b) of strawberry.

content. LOX activity increased during $6 \mathrm{~d}$ cold storage, suggesting that the dioxygenation of polyunsaturated fatty acids produced toxic hydroperoxy fatty acids and consequent membrane damage. LOX activity of control was higher than that of polysaccharide-coated fruits. Chitosancoated fruits showed the lowest LOX activity amongst three polysaccharide treatments on day 14 . Chitosan coating also significantly delayed LOX activity peak compared to control.

3.5. Effect of Polysaccharide-Based Edible Coatings on Oxidative Stress. The activities of antioxidative enzymes (POD, SOD, CAT, and APX) in polysaccharide-coated fruits were shown in Figure 5. POD activity is involved in plant senescence and stress through membrane alteration and lipid degradation. From Figure 5(a), POD activity in all fruits decreased during $16 \mathrm{~d}$ storage, and POD activity in polysaccharide-coated fruits showed higher level compared to control. Chitosan coating induced significantly higher $(p<$ $0.05)$ POD activity after day 10 compared to alginate and pullulan coating. From Figure 5(b), SOD activity in all fruits increased within the first two days and then decreased. Chitosan-coated fruits presented the highest SOD activity amongst three polysaccharide treatments after $6 \mathrm{~d}$ storage. From Figure 5(c), CAT activity in all fruits decreased during refrigerated storage, but the activity in control decreased more rapidly than that in polysaccharide-coated fruits. Chitosan-coated fruits showed the highest CAT activity amongst three polysaccharide treatments. Similar to CAT activity, APX activity in all fruits decreased rapidly during storage, and chitosan coating significantly reduced $(p<0.05)$ the decrease in APX activity after $6 \mathrm{~d}$ storage (Figure 5(d)).

\section{Discussion}

Edible coatings are proposed as viable alternatives for the preservation of fresh food such as fruit, vegetable, fish, and meat due to their capabilities to prevent moisture loss, aromas loss, solute transport, water absorption in food matrix, or oxygen penetration [23]. Edible coatings from polysaccharides have been applied to extend shelf life and preserve quality of foods. Polysaccharides such as chitosan, alginate, pullulan, gellan, and starch have been reported as raw materials to prepare edible coatings, which can be used as packaging materials for food preservation [24].

Recently, several polysaccharide-based edible coatings were successfully applied for preserving fruits such as orange, apple, mango, banana, papaya, citrus, and grapefruit [2527]. The influence of polysaccharide-based edible coatings (chitosan, alginate, and pullulan) on quality and antioxidant enzyme system of strawberries was discussed in this study. Polysaccharide coatings showed a significant delay in strawberry softening and rot, which reduced TSS and TA content changes during $16 \mathrm{~d}$ storage at $4^{\circ} \mathrm{C}$ (Figures $2(\mathrm{a})$ and $2(\mathrm{~b})$ ). Polysaccharide coatings also maintained higher VC and TP contents than control from day 2 and inhibited strawberry fruit respiration and membrane damage (Figures 2(c) and 2(d)). Similar results were found in cherry tomatoes, apples, citrus fruits, and so on.

Antioxidant enzymes play a very important role in inhibiting oxidative stress. POD, CAT, SOD, and APX are important enzymes, protecting cells from oxidative damage by scavenging ROS [18]. ROS accumulation causes oxidative injury, accelerating senescence progression and various senescenceassociated disorders. In this study, polysaccharide-coated fruits maintained significantly higher POD, CAT, SOD, and APX activities compared to control when storing at low temperatures (Figure 5). These antioxidative enzymes can scavenge overproduced ROS in fruit, retard peroxidation of membrane lipids, postpone loss of membrane function, alleviate oxidative stress of postharvest fruit, and therefore control strawberry senescence during storage to some extent. Consequently, polysaccharide-based edible coatings inhibited oxidative stress and ROS overproduction mainly by maintaining high activity of antioxidative enzymes in strawberry fruits. 


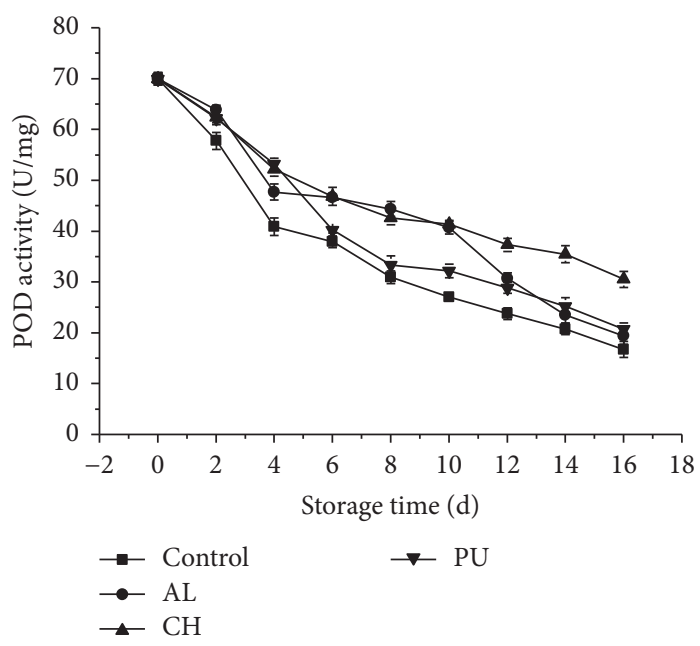

(a)

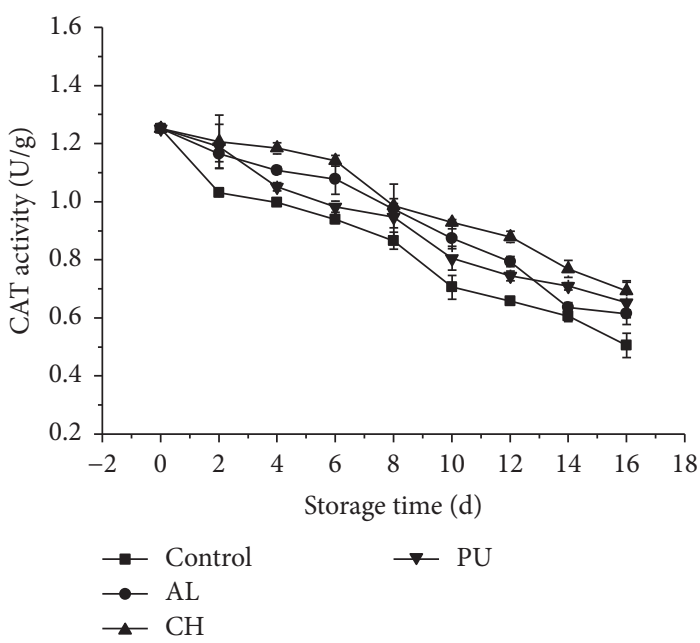

(c)

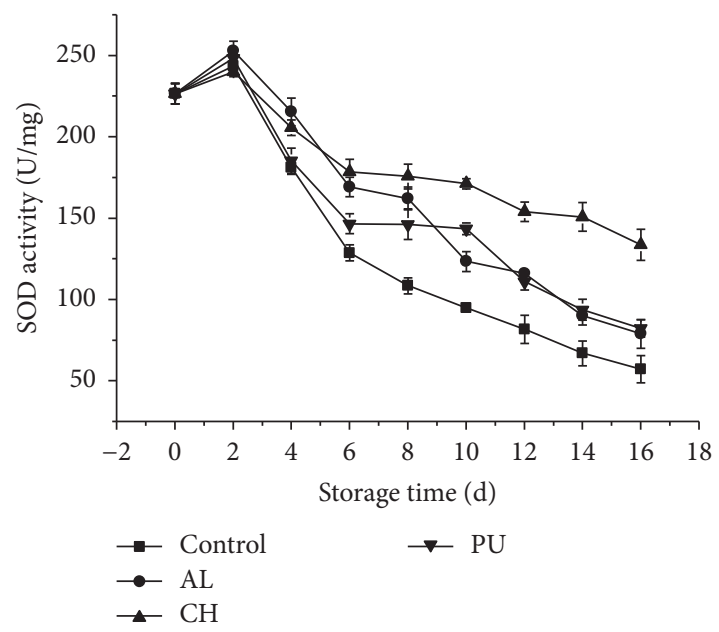

(b)

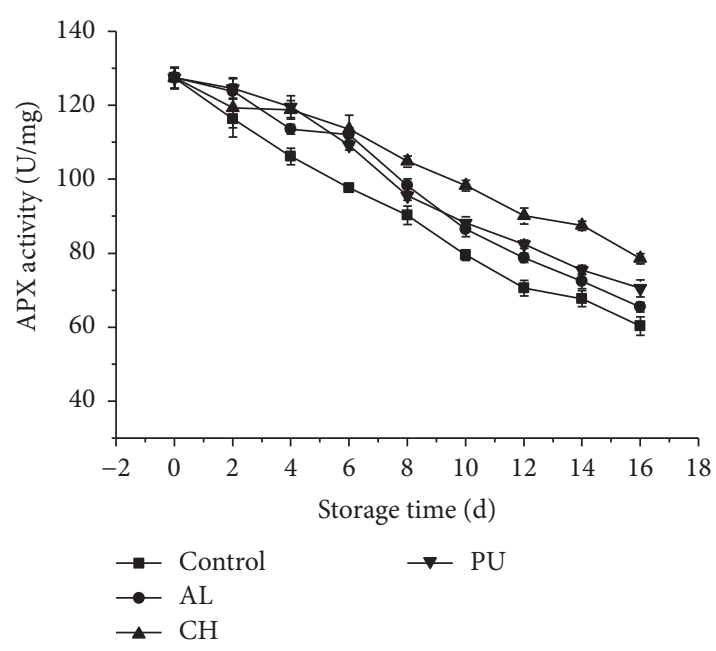

(d)

FIGURE 5: Effects of three different polysaccharide-based edible coatings on POD (a), SOD (b), CAT (c), and APX (d) activities of strawberry.

Chitosan-based coating was concerned in recent years owing to its nontoxic, biodegradable and biocompatible properties. Chitosan is obtained by alkaline $\mathrm{N}$-deacetylation of chitin, with a linear polysaccharide consisting of $(1,4)$ linked 2-amino-deoxy- $\beta$-D-glucan. Chitosan has attracted attention as a potential food preservative due to its antimicrobial activity against a wide range of fungi, yeasts, and bacteria $[28,29]$. In this study, chitosan had the most positive effects on strawberry fruit quality amongst three polysaccharides (Figures 1-3). Unlike other polysaccharide coating materials, chitosan has ability to resist several fungi and induce defense enzymes such as chitinase and chitosanase, which are associated with induced systemic resistance of fruits [30]. Chitosancoated fruits maintained significantly high POD, CAT, SOD, and APX activities on the 16 th day of storage at $4^{\circ} \mathrm{C}$ (Figure 5 ). These antioxidative enzymes could scavenge overproduced ROS in strawberries, retard peroxidation of membrane lipids, postpone loss of membrane function, alleviate fruit oxidative stress, and therefore control senescence during storage of strawberries.
In summary, polysaccharide coatings application delayed softening and slowed senescence and decay of strawberries by protecting membrane structure from peroxidation. Polysaccharide coatings are helpful to extend shelf life and maintain appearance and nutritional values during storage of strawberries. Polysaccharide-coated fruits also showed differential activities of antioxidant enzymes during storage at low temperature, which warranted further investigations on its effects on gene expression related to these enzymes. Whether polysaccharides can regulate ripening and senescence related gene needs to be ascertained in future research.

\section{Conflicts of Interest}

The authors declare that there are no conflicts of interest regarding the publication of this paper.

\section{Acknowledgments}

This research was supported by Special Fund for Agro-Scientific Research in the Public Interest (Grant no. 201303073), 
National Natural Science Foundation of China (Grant nos. 31160407, 31000927, 31560467, 31660589, and 31560006), Bagui Scholars Project Special Fund (Grant no. [2016]21), Technology Foundation for Selected Overseas Chinese Scholar, Ministry of Personnel of China (Grant no. Ren She Ting Han [2015]192), Guangxi Natural Science Foundation (Grant nos. 2014GXNSFDA118013, 2015GXNSFBA139102), Guangxi Agricultural Key Science and Technology Program (Grant no. 201527), Guangxi Scientific Research and Technological Development Projects (Grant nos. GuiKeAD16380015, 15104001-2), and Foundation of Fundamental Research Project from Guangxi Academy of Agricultural Sciences (Grant nos. 2015YT86, 2016JZ11, and 2017JZ10).

\section{References}

[1] T. A. Nasrin, M. A. Rahman, M. A. Hossain, M. N. Islam, and M. S. Arfin, "Postharvest quality response of strawberries with aloe vera coating during refrigerated storage," The Journal of Horticultural Science and Biotechnology, pp. 1-8, 2017.

[2] A. C. Guerreiro, C. M. L. Gago, M. L. Faleiro, M. G. C. Miguel, and M. D. C. Antunes, "The use of polysaccharide-based edible coatings enriched with essential oils to improve shelf-life of strawberries," Postharvest Biology and Technology, vol. 110, pp. 51-60, 2015.

[3] E. Velickova, E. Winkelhausen, S. Kuzmanova, V. D. Alves, and M. Moldão-Martins, "Impact of chitosan-beeswax edible coatings on the quality of fresh strawberries (Fragaria ananassa cv Camarosa) under commercial storage conditions," LWT Food Science and Technology, vol. 52, no. 2, pp. 80-92, 2013.

[4] R. Bhat and R. Stamminger, "Preserving strawberry quality by employing novel food preservation and processing techniques recent updates and future scope - an overview," Journal of Food Process Engineering, vol. 38, no. 6, pp. 536-554, 2015.

[5] C. Zhang, T. F. Garrison, S. A. Madbouly, and M. R. Kessler, "Recent advances in vegetable oil-based polymers and their composites," Progress in Polymer Science, vol. 71, pp. 91-143, 2016.

[6] M. Petriccione, F. Mastrobuoni, M. S. Pasquariello et al., "Effect of chitosan coating on the postharvest quality and antioxidant enzyme system response of strawberry fruit during cold storage," Foods, vol. 4, no. 4, pp. 501-523, 2015.

[7] A. C. Guerreiro, C. M. L. Gago, M. L. Faleiro, M. G. C. Miguel, and M. D. C. Antunes, "Edible coatings enriched with essential oils for extending the shelf-life of 'Bravo de Esmolfe' fresh-cut apples," International Journal of Food Science \& Technology, vol. 51, no. 1, pp. 87-95, 2016.

[8] C. Zhang, S. A. Madbouly, and M. R. Kessler, "Renewable polymers prepared from vanillin and its derivatives," Macromolecular Chemistry and Physics, vol. 216, no. 17, pp. 1816-1822, 2015.

[9] C. Chen, X. Peng, R. Zeng, M. Chen, C. Wan, and J. Chen, "Ficus hirta fruits extract incorporated into an alginate-based edible coating for Nanfeng mandarin preservation," Scientia Horticulturae, vol. 202, pp. 41-48, 2016.

[10] P.-J. Chien, F. Sheu, and F.-H. Yang, "Effects of edible chitosan coating on quality and shelf life of sliced mango fruit," Journal of Food Engineering, vol. 78, no. 1, pp. 225-229, 2007.

[11] F. Mancini and T. H. McHugh, "Fruit-alginate interactions in novel restructured products.," Die Nahrung, vol. 44, no. 3, pp. 152-157, 2000.
[12] C. Han, C. Lederer, M. McDaniel, and Y. Zhao, "Sensory evaluation of fresh strawberries (Fragaria ananassa) coated with chitosan-based edible coatings," Journal of Food Science, vol. 70, no. 3, pp. S172-S178, 2005.

[13] A. Chlebowska-Śmigiel and M. Gniewosz, "Effect of pullulan coating on inhibition of chosen microorganisms growth," ACTA Scientiarum Polonorum Technologia Alimentaria, vol. 8, no. 3, pp. 37-46, 2009.

[14] J. Sun, C. Li, K. Nagendra Prasad et al., "Membrane deterioration, enzymatic browning and oxidative stress in fresh fruits of three litchi cultivars during six-day storage," Scientia Horticulturae, vol. 148, pp. 97-103, 2012.

[15] B. Axelrod, T. M. Cheesbrough, and S. Leakso, "Lipoxygenase from soybeans," Methods in Enzymology, vol. 7, pp. 443-451, 1981.

[16] X. Zheng, S. Tian, M. J. Gidley, H. Yue, and B. Li, "Effects of exogenous oxalic acid on ripening and decay incidence in mango fruit during storage at room temperature," Postharvest Biology and Technology, vol. 45, no. 2, pp. 281-284, 2007.

[17] AOAC, Official Methods of Analysis Association of Official Analytical Chemists, AOAC, Virginia, Va, USA, 2000.

[18] J. Sun, X. You, L. Li et al., "Effects of a phospholipase D inhibitor on postharvest enzymatic browning and oxidative stress of litchi fruit," Postharvest Biology and Technology, vol. 62, no. 3, pp. 288294, 2011.

[19] Y. Nakano and K. Asada, "Hydrogen peroxide is scavenged by ascorbate-specific peroxidase in spinach chloroplasts," Plant \& Cell Physiology (PCP), vol. 22, no. 5, pp. 867-880, 1981.

[20] L.-L. Song, H. Liu, Y.-L. You et al., "Quality deterioration of cut carnation flowers involves in antioxidant systems and energy status," Scientia Horticulturae, vol. 170, pp. 45-52, 2014.

[21] S. Azarabadi, H. Abdollahi, M. Torabi, Z. Salehi, and J. Nasiri, "ROS generation, oxidative burst and dynamic expression profiles of ROS-scavenging enzymes of superoxide dismutase $(S O D)$, catalase $(C A T)$ and ascorbate peroxidase $(A P X)$ in response to Erwinia amylovora in pear (Pyrus communis L)," European Journal of Plant Pathology, vol. 147, no. 2, pp. 279-294, 2017.

[22] K. Mondal, N. S. Sharma, S. P. Malhotra, K. Dhawan, and R. Singh, "Oxidative stress and antioxidant systems in tomato fruits during storage," Journal of Food Biochemistry, vol. 27, no. 6, pp. 515-527, 2003.

[23] S. Tripathi, G. K. Mehrotra, and P. K. Dutta, "Chitosan based antimicrobial films for food packaging applications," e-Polymers, vol. 8, no. 1, pp. 1082-1088, 2008.

[24] S. Salman, F. Balci, A. F. Caglar, S. Tekin, M. Torun, and F. Ozdemir, "Effect of pullulan, sodium alginate and pectin based edible coatings on the quality of fresh-cut kiwi fruit during cold storage," Innovations in Food Packaging, Shelf Life and Food Safety, 2015.

[25] M. A. Rojas-Graü, M. S. Tapia, and O. Martín-Belloso, “Using polysaccharide-based edible coatings to maintain quality of fresh-cut Fuji apples," LWT- Food Science and Technology, vol. 41, no. 1, pp. 139-147, 2008.

[26] P. B. Vyas, "Postharvest quality maintenance of papaya fruit using polysaccharide-based edible coatings," International Journal of Fruit Science, vol. 14, no. 1, pp. 81-94, 2014.

[27] H. Arnon, R. Granit, R. Porat, and E. Poverenov, "Development of polysaccharides-based edible coatings for citrus fruits: a layer-by-layer approach," Food Chemistry, vol. 166, pp. 465-472, 2015. 
[28] Y. Xin, F. Chen, S. Lai, and H. Yang, "Influence of chitosanbased coatings on the physicochemical properties and pectin nanostructure of Chinese cherry," Postharvest Biology and Technology, vol. 133, pp. 64-71, 2017.

[29] A. Mohammadi, M. Hashemi, and S. M. Hosseini, "Postharvest treatment of nanochitosan-based coating loaded with Zataria multiflora essential oil improves antioxidant activity and extends shelf-life of cucumber," Innovative Food Science and Emerging Technologies, vol. 33, pp. 580-588, 2016.

[30] R. Irkin and M. Guldas, "Chitosan coating of red table grapes and fresh-cut honey melons to inhibit Fusarium Oxysporum growth," Journal of Food Processing and Preservation, vol. 38, no. 4, pp. 1948-1956, 2014. 

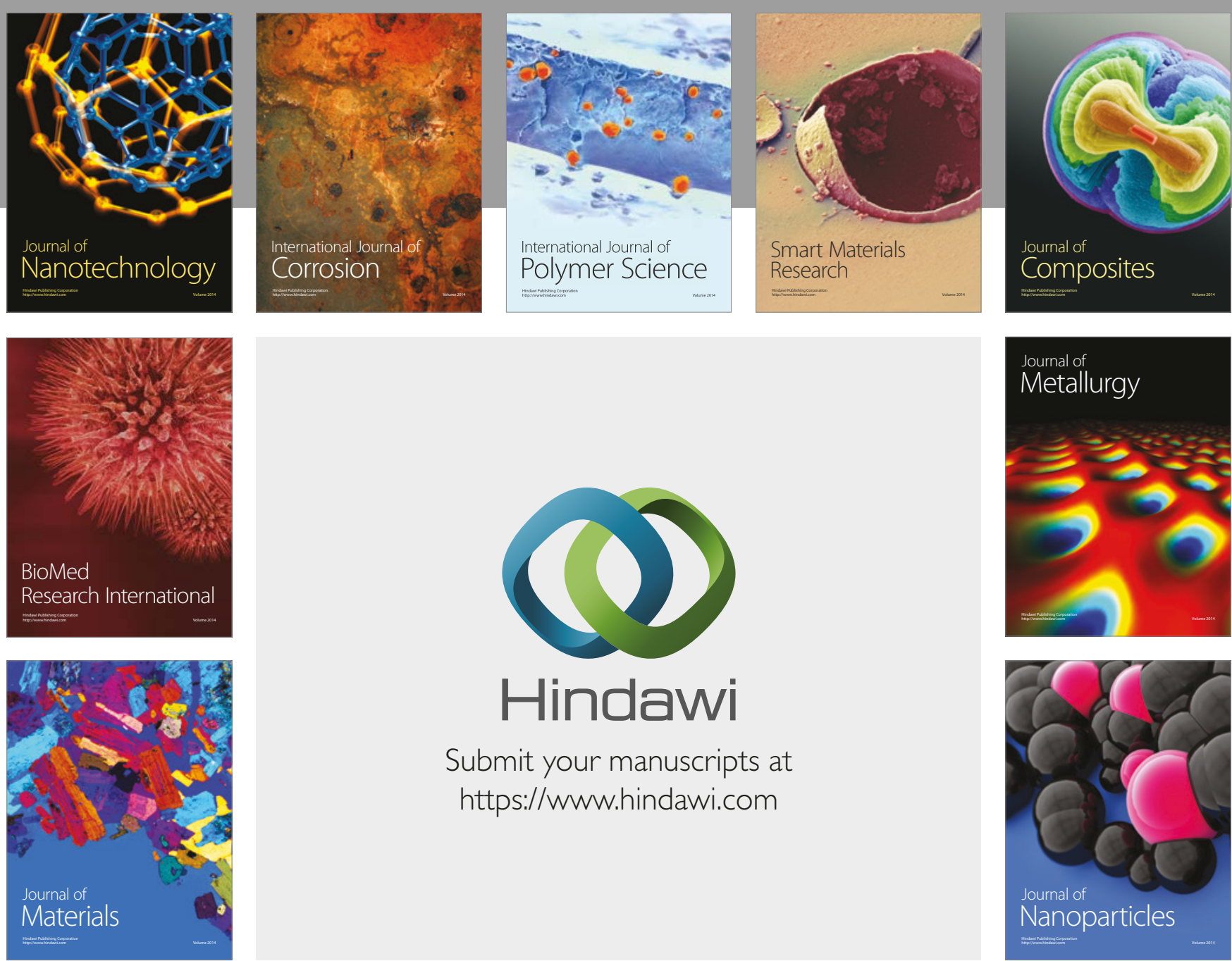

\section{Hindawi}

Submit your manuscripts at

https://www.hindawi.com
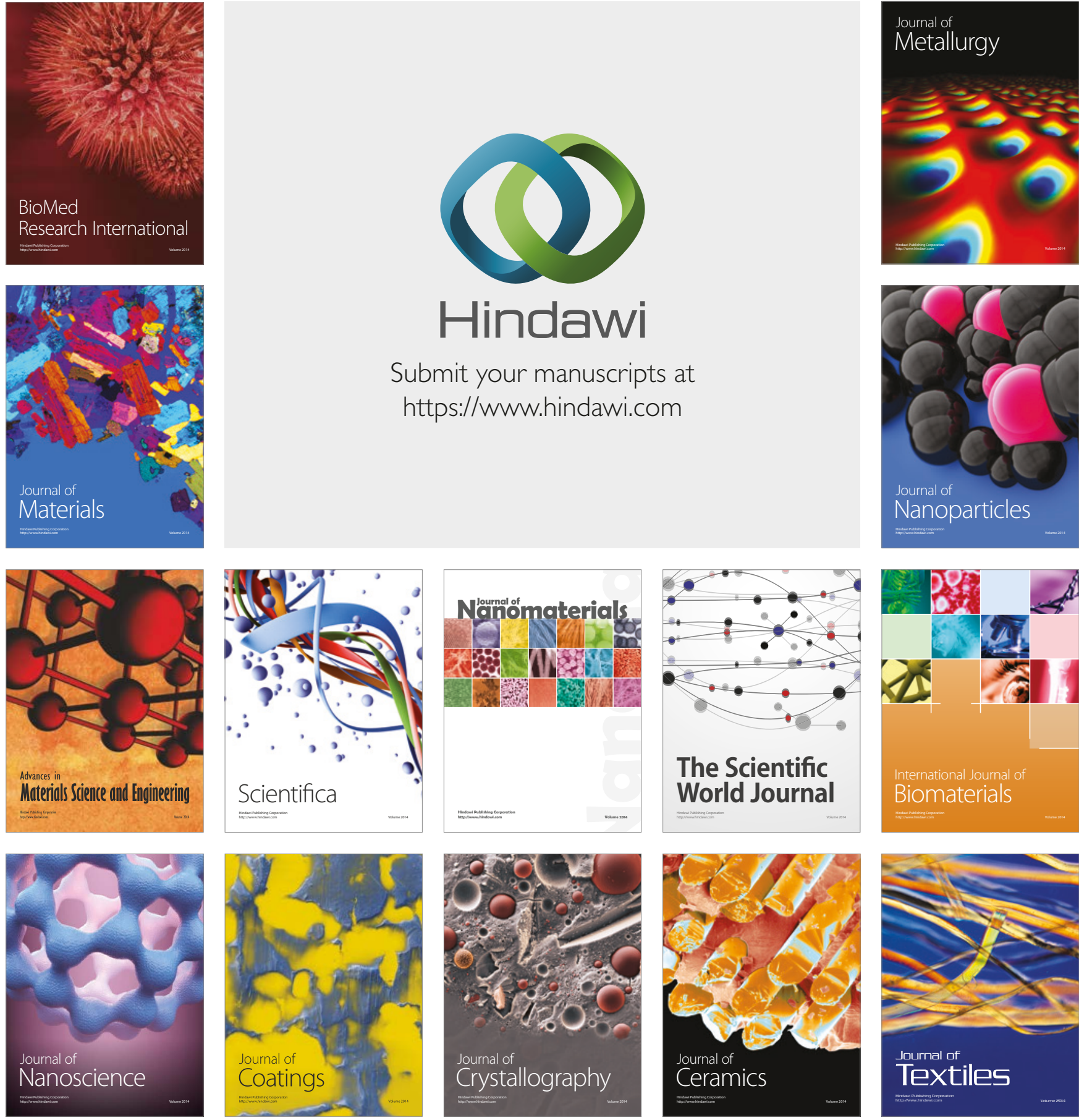

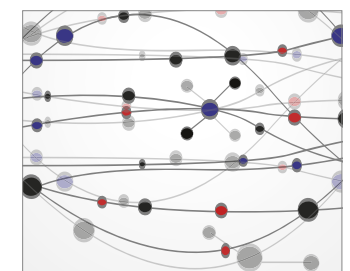

The Scientific World Journal
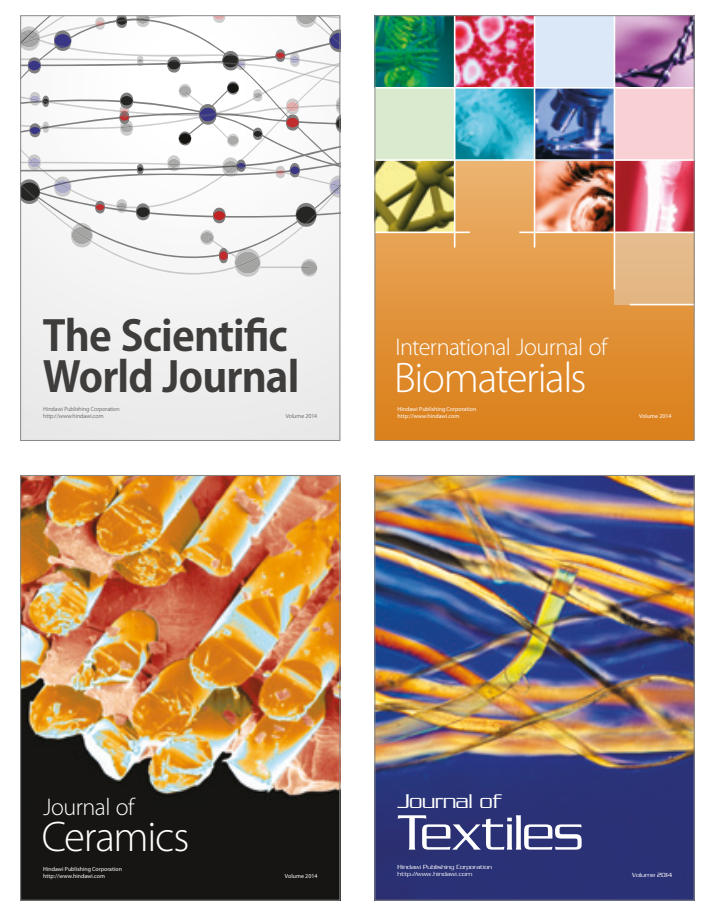